\title{
Computing Concentration Distribution of Lump Additives in Argon-stirred Melt
}

\author{
KYRYLO S. KRASNIKOV \\ Dniprovskyi State Technical University, Systems software department, Kamianske, Ukraine, \\ (e-mail: kir_kras@ukr.net),www.scitensor.com/lab/metallurgy/ladle/lumps \\ Corresponding author: Kyrylo S. Krasnikov (e-mail: kir_kras@ukr.net).
}

Author thanks to the scientists of Institute of Ferrous Mettalurgy of NANU for the details of considered metallurgical process, especially - to V. P. Pityuk and S. V. Grekov. Also they check adequacy of the mathematical model using colored ice balls added to a cylindrical reservoir with air-stirred water and video fixation from top and side view.

\begin{abstract}
: ABSTRACT To modify easily chemical consistence of molten steel metallurgical plants usually add alloys in a form of lumps through a hopper at ladle`s top. The problem is a large variety of adjusted technological conditions for this process, which leads to iterative discovery of rational ones. The article presents synthesis of a mathematical model for the mentioned process using Navier-Stokes and Euler-Lagrange equations. It is designed for researching of process modes depending on: a horizontal position of addition hopper relatively to argon plug at ladle bottom, an average diameter of spherical addition lumps, a total mass of addition heap, a necessity of the second hopper, a temperature of the melt. It takes into account interconnected three-dimensional fluid and solids dynamics, temperature exchange between melt and lump, also it computes level of concentration homogenization. A numerical experiment shows a significantly better addition homogenization when two hoppers are simultaneously used for a feeding. Adequacy checks are performed using ice balls in air-stirred water.
\end{abstract}

KEYWORDS Navier-Stokes equations; Euler-Lagrange equations; Secondary steelmaking; Argon blowing; Lump additives.

\section{INTRODUCTION}

\section{A. TOPICALITY}

$\mathrm{O}$ NE of the simple methods of a chemical modification for molten steel is alloys injection in a form of lumps (additives). Many metallurgical plants in the world use this method in secondary steelmaking. According to the method, additive lumps are stored in a bunker above ladle. At specified moment of time, bunker opens and lumps freely fall through a tube connected to the hole at ladle's cover (additive hopper). At the end of the fall, lumps enters ladle with molten steel and dissolve spreading around. Cold lumps decrease temperature of fluid, so melt needs mixing. Variety of technological parameters leads to finding of rational ones, including place of lumps fall relative to argon plug, average diameter of lumps, mass of a whole addition heap, necessity of the second hopper (two heaps of lumps are injected simultaneously), temperature of the melt, and others. Mathematical modeling can give satisfactory answers to these important questions at a relatively low cost, comparing to a laboratory or plant experiment.

\section{B. RELATED WORKS}

A popularity of the process caused a great interest of scientists to research the considered process in details. For example, in [1] authors simulate a spherical alloy lump melting with steel shell formation. They check adequacy of model with different sizes and materials of addition, as well as speed of steel. It is considered a single lump, however, in reality a big group of lumps with different sizes are added to melt. Authors of [2] also present model of single additive lump melting in form of cylinder with few moving fronts of freezing.

Authors of [3] find the rate of change in the radius of alloy particle from heat and mass flow balance to predict dissolution of additive with high melting temperature. 
In the paper [4], it is presented simulation of adding aluminum particles during RH Refining process. Multiphase flow of melt is taken into account.

A comparison of different approaches to model scrap melting can be made as demonstrated in $[5,6]$. Authors take into account mass and heat transfer. Finite difference method shows good results.

A number of works [7-12] use Navier-Stokes equations to simulate flow of fluid with addition. An interaction of two immiscible phases of fluid (for instance, melt-slag) can be modeled using level-set method as illustrated in $[13,14]$.

Dynamics of the melt free surface in ladle operations is often modeled by Volume of Fluid (VOF) method [15-19]. In addition, the authors use VOF to predict argon bubbles in molten steel and calculate drag force for them.

In [20] there is a summary of methods used by scientists for mathematical and physical modeling of tundish operations. It is considered RANS and LES approaches, as well as turbulence models.

In [21] the authors model melting of spherical aluminum particle in melt dividing sphere on three layers: solid core, melted aluminum and shell of cooled melt. The method allows them to take shell formation into account, because it affects melting.

Analyzed works make good starting basis for interconnected simulation of multibody, fluid dynamics and heat transfer.

\section{PURPOSE OF THE RESEARCH}

The aim of this work is synthesis of a mathematical model of steel feeding by bulk materials from hopper. The model takes into account important physical processes: solids-melt interaction, hydrodynamics, addition mixing and temperature exchange between melt and lumps of addition. For the experiment, a comparison of mixing effectiveness should be made with a single hopper and the two ones.

\section{MATHEMATICAL MODEL}

\section{A. ASSUMPTIONS}

To simplify the process prediction some idealizations are made:

1) Molten steel has a flat surface and a cylindrical shape (Fig. 1).

2) Molten steel is viscous incompressible Newtonian fluid - continuum.

3) Lumps of addition have spherical form with different diameter. The normal distribution of diameter in a heap is used. A sphere elastically collides with others. In addition, it experiences friction force from touched neighbors. Rotational speeds are ignorable small.

4) Spherical lumps are melted uniformly with crust formation in the beginning. There is absence of internal heat sources inside the lump. The spheres don't change volume of melt.
5) Argon bubbles are formed at ladle bottom near blowing plug. They are represented by continuum, which floats up with constant speed relative to the melt.

6) Slag layer is neglectable thin.

On the figure:

1 - addition hoppers, which are about 3 meters above a metal surface (at plants only one hopper is often used, but it is interest to try two of them);

2 - blowing plug for argon stirring of molten steel;

3 - places where groups of lumps enter the melt with natural spreading after falling from hoppers.

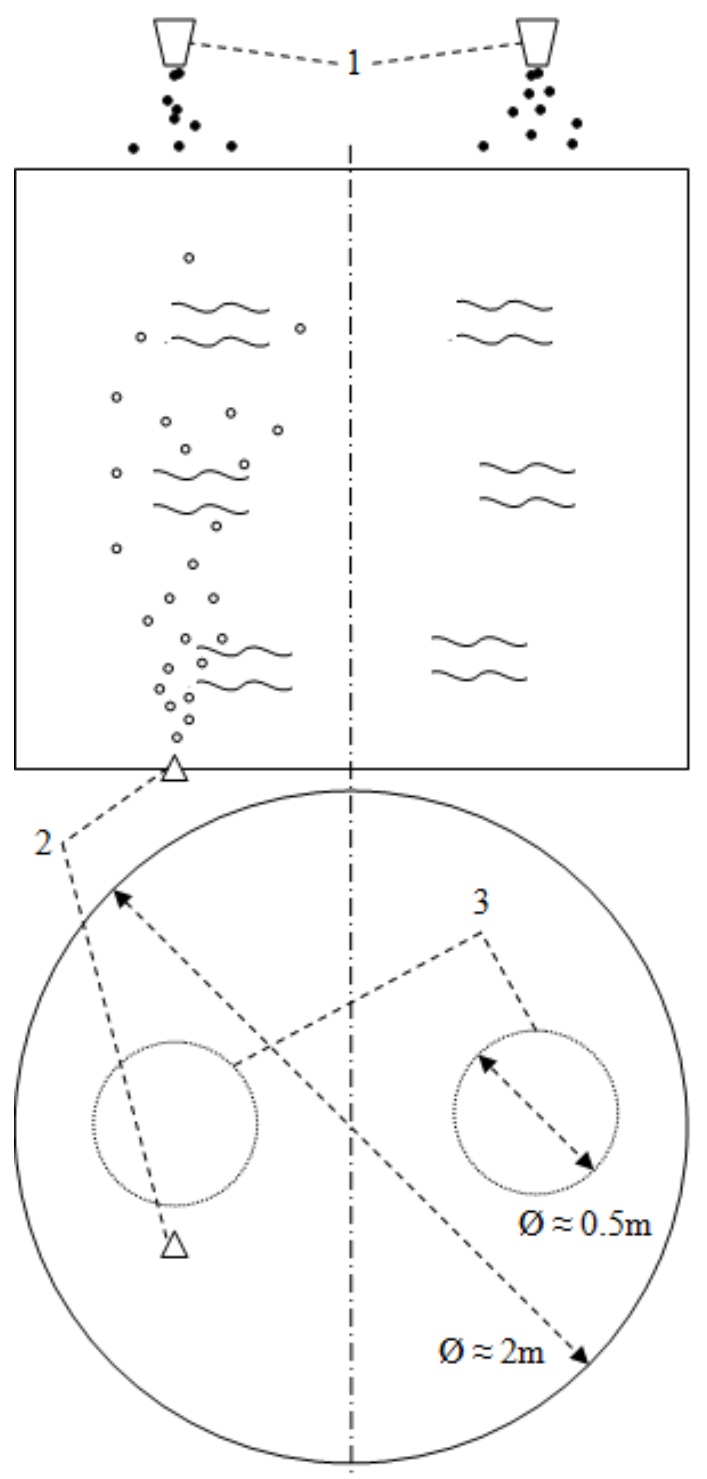

Figure 1. Cylindrical geometry of the melt body.

\section{B. MOTION OF MELT}

According to the conservation of impulse, mass and heat laws a hydrodynamics of a melt is defined by Navier-Stokes equations [10], as well as gas, addition concentration and temperature distributions are determined by diffusionconvection equation: 


$$
\begin{gathered}
\frac{\partial \vec{v}}{\partial t}+\vec{v} \cdot \nabla \vec{v}=-\nabla p^{\prime}+\nabla \cdot(D \nabla \vec{v})+\vec{F}, \\
\nabla \cdot \vec{v}=0 \\
\frac{\partial \alpha}{\partial t}+\nabla \cdot(\alpha \vec{v})=\nabla \cdot\left(D_{\alpha} \nabla \alpha\right)+q \frac{(T-300)}{300}, \\
\frac{\partial c}{\partial t}+\nabla \cdot(c \vec{v})=\nabla \cdot\left(D_{c} \nabla c\right)+\psi_{c}, \\
C \rho V\left(\frac{\partial T}{\partial t}+\nabla \cdot(T \vec{v})\right)=\nabla \cdot\left(D_{T} \nabla T\right)-\psi_{T},
\end{gathered}
$$

where $p^{\prime}$ and $D$ - kinematic pressure and coefficient of kinematic viscosity (result of dividing by melt density), $a-$ gas fraction, $q$ - argon volume per second, $T$ - average melt temperature, 300 - average argon temperature before entering melt, $\psi_{c}$-addition flux from lumps, $\psi_{T}$ - heat flux to addition lumps, expressed below at section 2.4.

$$
\vec{F}=-(1-a) \vec{g}+\frac{1}{\rho} \sum_{i} \vec{F}_{i}^{D}
$$

where $\rho$ - density of molten metal.

The force of hydrodynamic drag is [20]:

$$
\vec{F}_{i}^{D}=C_{D} \frac{\rho}{2} \pi R_{i}^{2}\left\|\dot{\vec{r}}_{i}-\vec{v}\right\|\left(\dot{\vec{r}}_{i}-\vec{v}\right)
$$

where $C_{D}$-dimensionless coefficient of drag (about 0,44 for sphere), $R_{i}$ and $\dot{\vec{r}}_{i}$ - radius and speed of $i$ sphere.

\section{MOTION OF SOLIDS}

Reference point is at center of ladle bottom. The cylindrical coordinate system fits geometry of a ladle. Therefore, define radius-vector of mass center for $i$ lump using $r-\varphi-z$ coordinates:

$$
\vec{r}_{i}=\left(r_{i} \cos \left(\varphi_{i}\right), r_{i} \sin \left(\varphi_{i}\right), z_{i}\right)
$$

Dynamics of spherical lumps are defined by EulerLagrange equations with term of hydrodynamic drag force, defined above:

$$
\frac{d}{d t} \frac{\partial K}{\partial \dot{q}_{k}}-\frac{\partial K}{\partial q_{k}}=-\frac{\partial P}{\partial q_{k}}+\vec{F}_{i}^{D} \cdot \frac{\partial \vec{r}_{i}}{\partial q_{k}}, k=1 . .3 N
$$

where $N$ - number of spheres.

Kinetic energy doesn`t include a rotation of a lump:

$$
K=\sum_{i=1}^{N} \frac{m_{i}}{2}\left(\dot{\vec{r}}_{i} \cdot \dot{\vec{r}}_{i}\right)
$$

Potential energy contains terms, which prevent excessive interpenetrations of solids $\left(P_{c}\right)$ and their passing through the ladle walls $\left(P_{w}\right)$ :

$$
\begin{gathered}
P=-\sum_{i=1}^{N} m_{i}\left(\vec{g} \cdot \vec{r}_{i}\right)+P_{c}+P_{w}, \\
P_{c}=\sum_{i=1}^{N} \sum_{j=1}^{N} \frac{k_{c}}{2}\left(\left\|\vec{r}_{i}-\vec{r}_{j}\right\|-R_{i}-R_{j}\right)^{2}, \\
P_{w}=\sum_{i=1}^{N}\left[\frac{k_{w}}{2}\left(r_{i}-r_{w}\right)^{2}+\frac{k_{b}}{2} z_{i}^{2}\right],
\end{gathered}
$$

where $r_{i}$ and $z_{i}$ - radial and height component of radiusvector $\overline{r_{i}}, r_{w}$ - radius of wall, $k_{c}$ - coefficient of restrain after collision of spheres (equals zero when $i$ equals $j$ or when spheres don` $t$ go through each other), $k_{w}$ and $k_{b}$-stiffness coefficients, which are sufficiently large when sphere outside the ladle and are zero when it is inside.

Let introduce some friction between near spheres to prevent fast divergence of spheres from falling place:

$$
F_{i}=\sum_{j \neq i} k_{f} \frac{\dot{\vec{r}}_{i}-\dot{\vec{r}}_{j}}{\left\|\vec{r}_{i}-\vec{r}_{j}\right\|} \quad i, j=\overline{1 . . N}
$$

where $k_{f}$ - coefficient of friction.

Initially a group of spheres with a small space between ones are randomly positioned above melt in form of cylinder with radius of spread and height depended on an overall addition mass and maximal diameter of sphere. One achieves a conical form of the group if initial distance from radiusvector $\vec{r}_{i}^{x y}$ to the axis of the hopper $\vec{a}^{x y}$ is dependent on the starting z-coordinate of radius-vector:

$$
\left\|\vec{r}_{i}^{x y}-\vec{a}^{x y}\right\|<\min \left(s, \frac{D^{\max }}{2}\left(1+k_{s} \vec{r}_{i}^{z}\right)\right),
$$

where $k_{s}$ - coefficient of cone slope, $s$ - maximum radius of spheres scattering from hopper axis $\vec{a}, D^{\max }$ - maximal diameter of sphere.

To get equations of motion, the derivatives of above energies are taken with respect to the generalized coordinates symbolically. Then, axis of time divided by layers with constant velocities and coordinates. Accelerations are defined using them and linear algebraic equations are got. Integration is performed by semi-implicit Euler`s method. 


\section{MELTING OF ADDITION}

Melting represented by the famous Stephan's problem. Boundary is moved by distance, which is determined from volume of melted material. The volume can be defined by amount of material warmed up to melting temperature. And slowing factor is heat capacity of material - the more it is the smaller volume of material is melted each second.

Knowing the molten volume $V$ results in determining the change in radius from the current time layer to the new one:

$$
R_{i}^{*}=\sqrt[3]{R_{i}^{3}-\frac{V}{4 / 3 \pi}}
$$

where $R_{i}{ }^{*}$ and $R_{i}$ - new and current radius of sphere; $V-$ volume of melted material, defined by heat balance.

The temperature of spherical lump is determined by Newton`s law of cooling and Fourier`s law:

$$
\begin{aligned}
\frac{d T_{i}^{\Theta}}{d t} & =\frac{\psi_{T}}{c^{\Theta}\left(T_{i}^{\Theta}\right)\left(\rho^{\Theta} 4 / 3 \pi r_{i}^{3}\right)} \\
\psi_{T} & =h\left(T-T_{i}^{\Theta}\right) 4 \pi r_{i}^{2}
\end{aligned}
$$

where $h$ - coefficient of heat transfer between surface with area $A$ and surrounding melt, $c^{\Theta}$ and $\rho^{\Theta}-$ specific heat capacity and density of addition material.

Boundary conditions are natural:

1) For velocity field, as well as, concentration and gas field, it is impermeability on the solid surfaces and on the top surface of melt (for a gas - outlet).

2) For temperature field it is heat flux to the surrounding ladle.

\section{E. INDICATORS}

There are summary numbers, which are useful for a researcher to analyze defined scalar fields as well as to check quantitative and qualitative adequacy. For example, overall mass of lumps, added to the ladle, must be conserved. Also points with an extremely low speed can be used to locate slowly mixing regions in the melt.

Homogenization level of temperature and addition concentration in a melt is determined by the coefficient of variation.

\section{F. IMPLEMENTATION}

The mathematical model is realized in computer program using C\# language. The program implements a solver, a visualizer and a file writer. The solver uses a standard central difference method for discretization of partial differential equations. The multithreading maximizes load of multicore processor, thus computational domain for melt body is divided along $\mathrm{z}$-axis with virtual layers assigned to corresponding threads. A looped barrier provides synchronization of these threads after stages of computation.
A tenth of second the file writer saves results with indicators (section 2.5) and the visualizer creates an image of $3 \mathrm{D}$ scene perspectively projected on a plane using view frustrum. The 3D scene represents state of mathematical model and consists of dynamically colored triangles. Vertex positions of the triangles are computed only once - at the beginning of the modeling. As consequence, a total time of scene visualization is ignorable smaller than a total time of model states calculation.

\section{RESULTS}

There are two conducted numerical experiments - the first one uses one hopper (Fig. 2), and the second one uses two hoppers (Fig. 3-4). Figure 5 shows comparison of additive concentration evolution for these two cases. During whole modeling time for double-hopper configuration, a coefficient of variation is lower than for single hopper. That is theoretically predictable behavior.

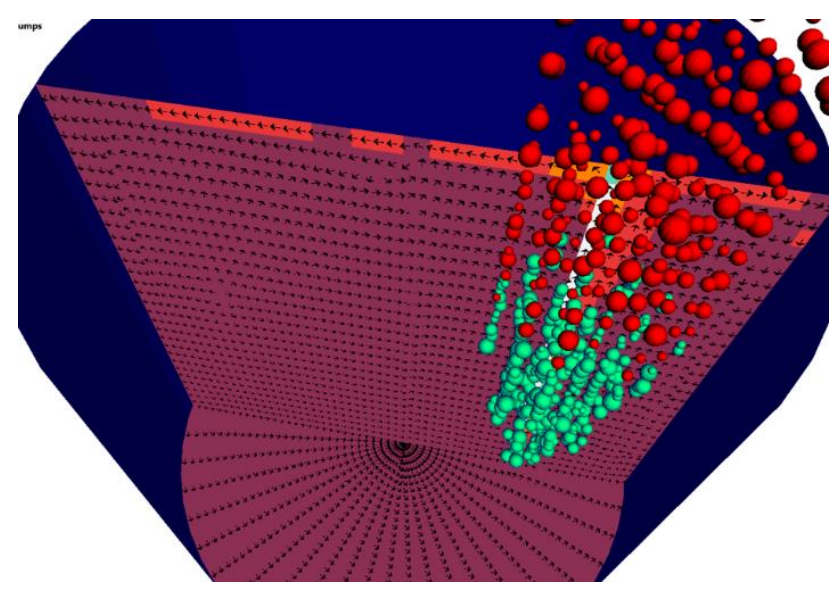

Figure 2. Comparison of mixing speed for one and two addition hoppers

At the beginning gas concentration $\alpha$ is zero and increases near argon plug. During that, input of argon the velocity field $\bar{v}$ forms vortices and vertical flux. The flux transport heat and mass from bottom to top layers of melt, where they horizontally spread to other places. A place that is distant from argon plug has low speed so more time is needed to reach average concentration and temperature in it.

Addition heap or group starts falling at 40 second and reached the melt with fully developed speed field. Active mixing provides fast homogenization of temperature and concentration, which is cardinally changed after touching with cold addition lumps.

The figures demonstrate a blue inner surface of ladle, vertical and horizontal cross-sections of speed field and addition lumps as spheres at 41 second of model time. Red spheres are above the top surface of melt and turquoise ones are under it. Black arrows represent direction of speed field: on the vertical cross section the direction consists from vertical and radial components of vector, on the horizontal cross section - from radial and azimuthal one. Background of each arrow represents magnitude of vector from crimson (low speed) to white (around $2 \mathrm{~m} / \mathrm{s}$ ). 


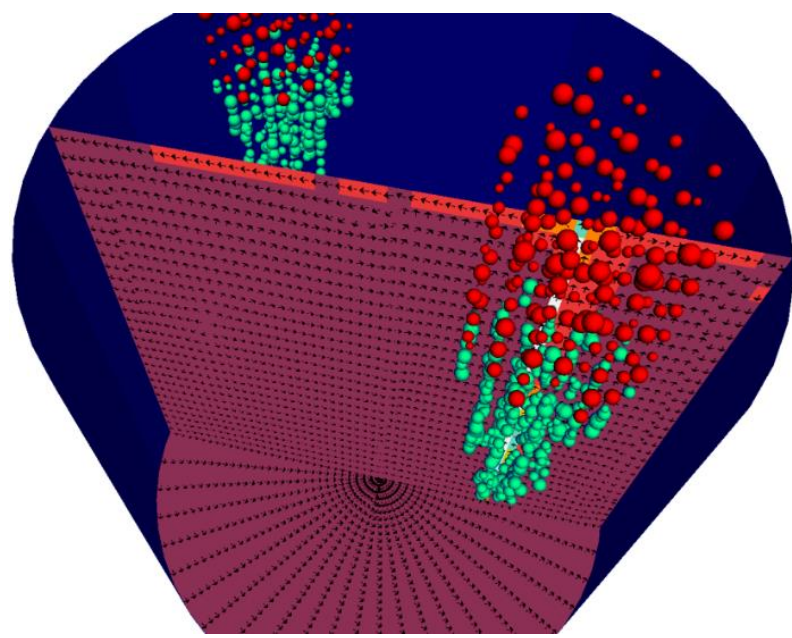

Figure 3. Comparison of mixing speed for one and two addition hoppers

On the figure 4 yellow volumes represent isosurface of dissolved addition concentration around $50 \mathrm{~kg} / \mathrm{m}^{3}$. It is seen two highly concentrated clusters formed from two groups of lumps, which are being deformed by melt speed field.

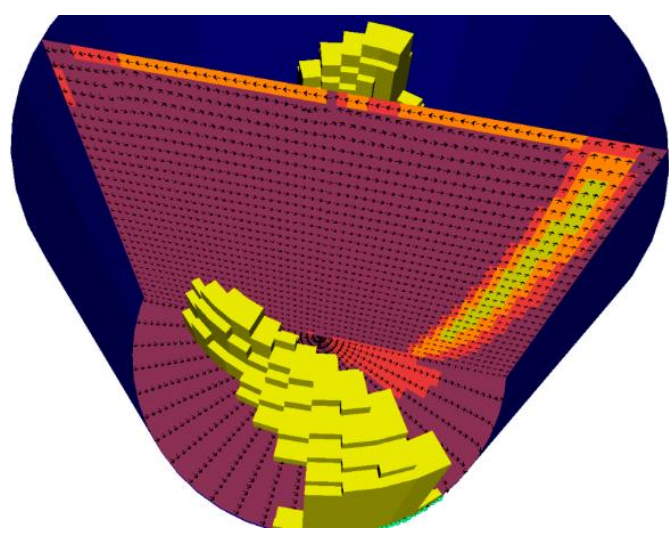

Figure 4. Situation at 79 second of model time Time, seconds

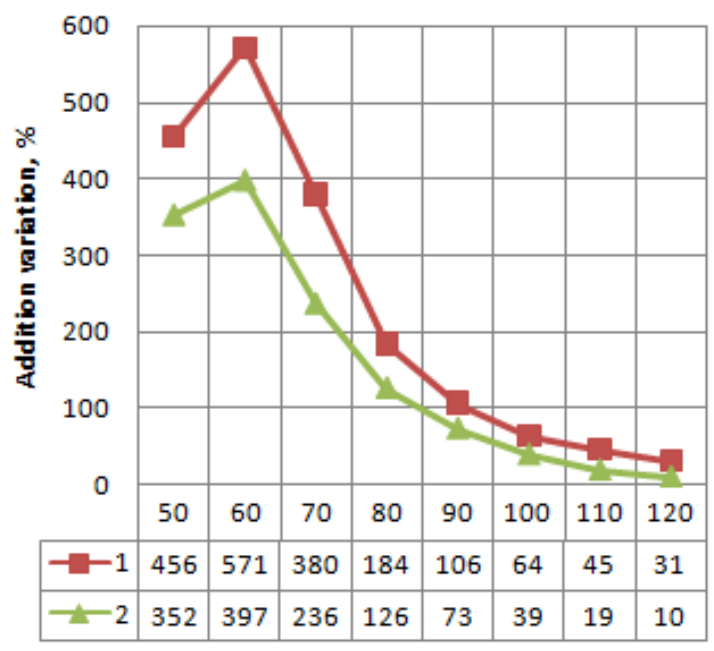

Figure 5. Comparison of addition variation for one and two addition hoppers (lower is better).

\section{CONCLUSIONS}

Presented 3D mathematical model of melt refining using injection of addition lumps from hopper predicts mixing phenomena in argon-stirred melt. It is used to compare addition mixing effectiveness in single-hopper and doublehopper configurations. As figure 5 shows, two hoppers significantly speed up homogenization of addition, thus it is recommended for realization at plant. A configuration with more than two hoppers can be difficult to implement and can decrease process effectiveness, because of temperature loss. During experiment it is detected change of temperature and speed of melt (around 14\%). They are mainly changed after lumps get under the surface of melt.

\section{References}

[1] P. Väyrynen, L. Holappa, S. Louhenkilpi. Simulation of melting of alloying materials in steel ladle, 2012, [Online]. Available at: www.flow3d.com/wp-content/uploads/2014/08/Simulation-ofMelting-ofAlloying-Materials-in-Steel-Ladle.pdf

[2] S. Prasad, A. Prasad, A. Kumar, "Study of axi-symmetric freezing and melting of an agitated bath material around a low melting temperature cylindrical solid additive," International Journal of Engineering, vol. XVI, pp. 53-66, 2018.

[3] L. Zhang, F. Oeters, "Melting and dissolution of high-melting alloys in steel melts," Steel Research, vol. 71, issue 5, pp. 141-144, 2000.

[4] C. Liu, H. Duan, L. Zhang, "Modeling of the melting of aluminum particles during the RH refining process," Metals, vol. 9, issue 4, art. no. 442 , pp. $1-13,2019$

[5] A. Shukla, B. Deo. "Scrap dissolution in molten iron containing carbon for the case of coupled heat and mass transfer control," Metallurgical and Materials Transactions, vol. B, pp. 1-22, 2013.

[6] G. Sethi, A. K. Shukla, P. C. Das, P. Chandra, B. Deo, "Theoretical aspects of scrap dissolution in oxygen steelmaking converters," in AISTech Proceedings, 2004, vol. II, pp. 915-926.

[7] L. Li, Z. Liu, B. Li, H. Matsuura, F. Tsukihashi, "Water model and CFD-PBM coupled model of gas-liquid-slag three-phase flow in ladle metallurgy," ISIJ International, vol. 55, issue 7, pp. 1337-1346, 2015.

[8] H. Ling, F. Li, L. Zhang, A.N. Conejo, "Investigation on the effect of nozzle number on the recirculation rate and mixing time in the $\mathrm{RH}$ process using VOF + DPM model," Metallurgical and Materials Transactions B: Process Metallurgy and Materials Processing Science, vol. 47, issue 3, pp. 1950-1961, 2016.

[9] D.-Q. Geng, J.-X. Zheng, K. Wang, P. Wang, R.-Q. Liang, H.-T. Liu, H. Lei, J.-C. He, "Simulation on decarburization and inclusion removal process in the Ruhrstahl-Heraeus (RH) process with ladle bottom blowing," Metallurgical and Materials Transactions B. Process Metallurgy and Materials Processing Science, vol. 46, issue 3, art. no. 314, pp. 1484-1493, 2015.

[10] U. Singh, R. Anapagaddi, S. Mangal, K.A. Padmanabhan, A.K. Singh, "Multiphase modeling of bottom-stirred ladle for prediction of slag-steel interface and estimation of desulfurization behavior," Metallurgical and Materials Transactions B: Process Metallurgy and Materials Processing Science, vol. 47, issue 3, pp. 1804-1816, 2016

[11] L. Li, X. Li, Z. Zhu, B. Li, "Numerical modeling of multiphase flow in gas stirred ladles: From a multiscale point of view," Powder Technology, vol. 373, pp. 14-25, 2020.

[12] J.E. Farrera-Buenrostro, C.A. Hernández-Bocanegra, J.A. RamosBanderas, E. Torres-Alonso, N.M. López-Granados, M.A. RamírezArgáez, "Analysis of temperature losses of the liquid steel in a ladle furnace during desulfurization stage," Transactions of the Indian Institute of Metals, vol. 72, issue 4, pp. 899-909, 2019.

[13] Y.-Y. Tsui, C.-Y. Liu, S.-W. Lin, "Coupled level-set and volume-offluid method for two-phase flow calculations," Numerical Heat Transfer, Part B: Fundamentals, vol. 71, issue 2, pp. 173-185, 2017.

[14] T. Nguyen Duy, T. Hino, "An improvement of interface computation of incompressible two-phase flows based on coupling volume of fluid 
with level-set methods," International Journal of Computational Fluid Dynamics, vol. 34, issue 1, pp. 75-89, 2020.

[15] Z. Zhi-jian, W. Min, S. Lei, B. Yan-ping, "Splashing simulation of liquid steel drops during the Ruhrstahl heraeus vacuum process," Metals, vol 10, pp. 1070-1084, 2020.

[16] Q. Cao, L. Nastac. "Mathematical investigation of fluid flow, mass transfer, and slag-steel interfacial behavior in Gasstirred ladles," The Minerals, Metals \& Materials Society and ASM International, vol. 49B, pp. 1388-1404, 2018.

[17] G. Chen, S. He, Y. Li, "Investigation of the air-argon-steel-slag flow in an industrial RH reactor with VOF-DPM coupled model," Metallurgical and Materials Transactions B: Process Metallurgy and Materials Processing Science, vol. 48, issue 4, pp. 2176-2186, 2017.

[18] C.A. Llanos, S. Garcia-Hernandez, J.A. Ramos-Banderas, J.J. De Barreto, G. Solorio-Diaz, "Multiphase modeling of the fluidynamics of bottom argon bubbling during ladle operations," ISIJ International, vol. 50, issue 3, pp. 396-402, 2010.

[19] E. K. Ramasetti, V.-V. Visuri, P. Sulasalmi, T. Fabritius, T. Saatio, M. Li, L. Shao "Numerical modeling of open-eye formation and mixing time in argon stirred industrial ladle," Metals, vol. 9, pp. 829$842,2019$.

[20] K. Chattopadhyay, M. Isac, R. I. L. Guthrie, "Physical and mathematical modelling of steelmaking tundish operations: A review of the last decade (1999-2009)," ISIJ International, vol. 50, no. 3, pp. 331-348, 2010

[21] B. Zhou, Y. Yongxiang M. A. Reuter, "Modelling of melting behaviour of aluminum metal in molten salt and metal bath," in
Proceedings of the TMS Annual Meeting: Yazawa International Symposium on Metallurgical and Materials Processing: Principles and Technologies, San Diego, California, March 3-6, 2003, vol. I, pp. 1249-1258.

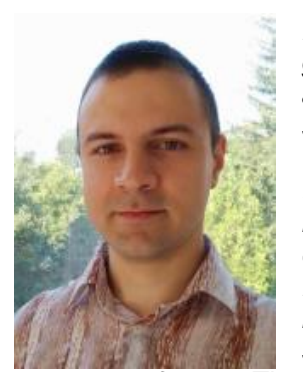

KYRYLO S. KRASNIKOV, in 2009 graduated from Faculty of Electronics and Computer Engineering, Dniprovskyi State Technical University (DSTU) with M.S. in Software Engineering. At the end of 2016 in National metallurgical academy of Ukraine he defended his thesis for the degree of $P h D$ in Mathematical simulation and methods of calculation. Present job: a senior lecturer at DSTU, Department of systems software. The scientific interests are focused on the application of Computational Fluid Dynamics, System of Solids Dynamics and Thermo-dynamics to the various problems in the ferrous metallurgy and other fields. Professional skills include software projecting using UML as well as programming using modern versions of $\mathrm{C}++_{+}$, C, Java and popular frameworks. 